\title{
DETECTION OF FOREST DISTURBANCE USING TANDEM-X POL-INSAR COHERENCE
}

\author{
M. Musthafa ${ }^{1, *}$, G. Singh ${ }^{1}$, U.Khati $^{1}$ \\ ${ }^{1}$ Centre of Studies in Resources Engineering, Indian Institute of Technology Bombay, India - smusthafa.md@ gmail.com
}

\author{
Commission V, SS: Natural Resources Management
}

KEY WORDS: Pol-InSAR coherence, TanDEM-X, Forest disturbance

\begin{abstract}
:
This current study shows the potential of TanDEM-X pol-InSAR coherence to identify progressive selective logging of Teak plantation in Uttarakhand, India. Pol-InSAR data were acquired over four months with 11 days interval with perpendicular baseline varying from 111 to $689 \mathrm{~m}$. Progressive selective logging of mature teak plantation from January to February was analyzed using time-series pol-InSAR coherences. The results shows the baseline selection critical for forest change studies. TanDEM-X derived pol-InSAR coherence would enable us to detect the change in forest structure with high reliability
\end{abstract}

\section{INTRODUCTION}

Forest degradation and deforestation accounts for $17 \%$ of global greenhouse gas emissions (Øystein Aasaaren et al., 2011), loss in biodiversity and ecosystem services (Reid et al., 2005). Inputs on accurate estimate on forest disturbance are emphasized in strategizing climate change mitigation measures, since forests plays key role in regulation mechanism on terrestrial ecosystem. With varying penetration capability depending on the wavelength of the SAR sensors, along with the advancement in techniques such as PolSAR and PolInSAR, SAR remote sensing has emerged as a suitable alternative to study forest structural changes such as phenology (Khati et al., 2017), clear cuts(Olesk et al., 2015) and growth dynamics (Kobayashi et al., 2015).

TerraSAR-X/TanDEM-X (TDM) satellite pair acquires single pass Pol-InSAR data with near zero temporal baseline thereby eliminating a source of decorrelation at the source level. Though with limited penetration capability, Pulella (A. Pulella et al., 2017) had shown the potential of TDM-X Pol-InSAR derived height and phase center in detecting forest disturbances. In this study, Pol-InSAR derived coherences of linear, Pauli and circular polarizations were utilized to assess its feasibility to detect progressive selective logging.

\section{DATA AND STUDY AREA}

Fully polarimetric TDM-X pol-InSAR data were acquired in pursuit monostatic mode during the month of December 2014 to March 2015 with 11 days interval. The characteristics of the data tabulated in Table 1 .

In situ forest inventory data comprising species information, age and forest measurable such as Circumference at breast height $(\mathrm{CBH})$, Lowrey's stand height and leaf area index (LAI) was collected during field campaigns conducted during NovemberDecember 2015 and March 2017. Secondary Forest data on harvest schedule and type of plantation to be harvested was collected from State Forest Department of Uttarakhand. The field data constituted species and age information along with the probable harvest schedule for multiple forest compartments.

\begin{tabular}{|c|c|c|c|}
\hline Sl. No & Date of Pass & Baseline (m) & $\begin{array}{l}\text { Incidence angle } \\
\left({ }^{\circ}\right)\end{array}$ \\
\hline 1 & 09 Dec 2014 & -171.09 & 44.26 \\
\hline 2 & 20 Dec 2014 & 111.00 & 44.23 \\
\hline 3 & 31 Dec 2014 & 413.00 & 44.23 \\
\hline 4 & 11 Jan 2015 & 689.00 & 44.31 \\
\hline 5 & 22 Jan 2015 & 590.00 & 44.34 \\
\hline 6 & 02 Feb 2015 & 281.00 & 44.31 \\
\hline 7 & 13 Feb 2015 & -185.00 & 44.22 \\
\hline 8 & 24 Feb 2015 & -524.04 & 44.24 \\
\hline 9 & 07 Mar 2015 & -616.32 & 44.21 \\
\hline
\end{tabular}

Table 1 Characteristics of TDM-X datasets utilized

The study area is part of central terai forest division, a managed plantation forest. The key rotation species of the forest division are Tectona grandis, Eucalyptus sp, Poplar sp, Holoptelia integrifolia, Trema orientalis, Cassia fistula and Dalbergia sissoo. Multiple mature Tectona grandis (Teak) plantation compartments harvested during January to March 2015 were selected for this study (Figure 1).

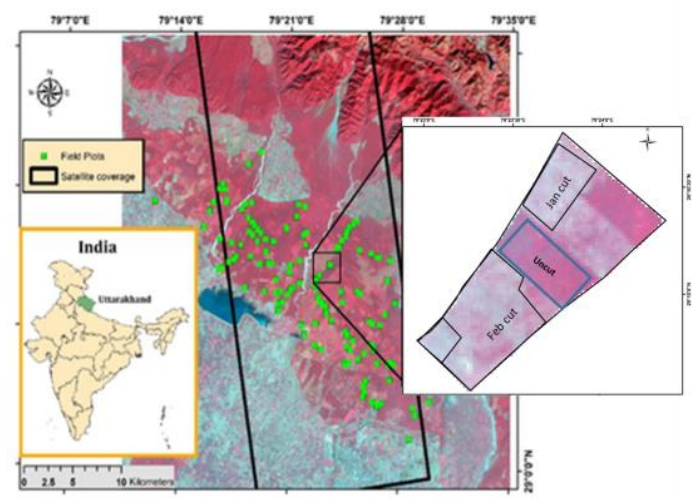

Figure 1 Study area showing Central Terai Forest Division. (Zoomed portion) Teak plantation compartments harvested during January to March 2015. Imagery - Landsat -8 FCC (March 2015)

\footnotetext{
${ }^{*}$ Corresponding author
} 


\section{METHODOLOGY}

TDM-X pol-InSAR pairs were calibrated to form Sinclair matrix [S2]. All the 9 pairs were co-registered for further processing. The scattering matrices of master and slave are represented by [S1] and [S2]. Pauli basis vectorized matrices were used to generate multilooked [T6] matrix from which complex coherence in various polarization basis denoted by the unitary complex vector $\vec{\omega}$, representing a polarization state are generated

$$
S_{1}(\vec{\omega})=\vec{\omega} \cdot \overrightarrow{k_{1}} \text { and } S_{2}(\vec{\omega})=\vec{\omega}^{\dagger} \cdot \overrightarrow{k_{2}}
$$

The interferometric coherence in each polarization state $\vec{\omega}$ can be given by

$$
(\omega)=\frac{\left(\vec{\omega}^{\dagger}\left[\Omega_{12}\right] \vec{\omega}\right)}{\sqrt{\left(\vec{\omega}+\left[T_{11}\right] \vec{\omega}\right)\left(\vec{\omega}^{\dagger}\left[T_{22}\right] \vec{\omega}\right)}}
$$

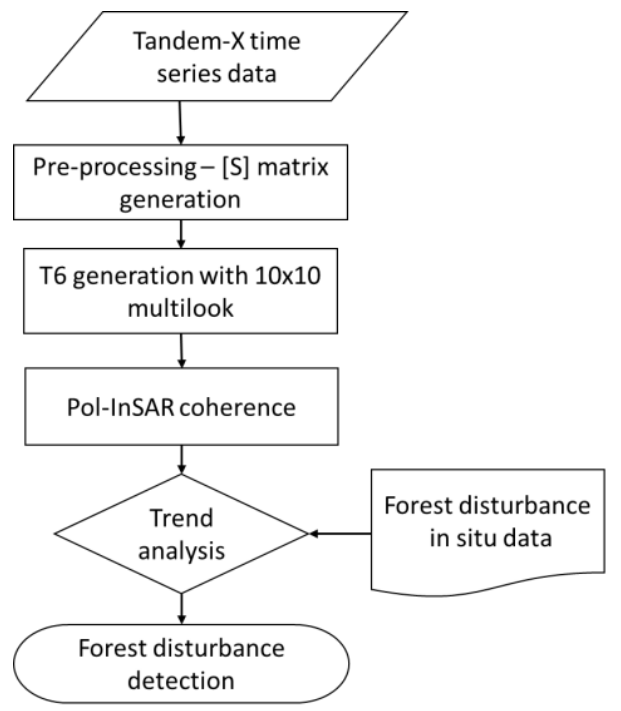

Figure 2 Flow chart

Where 6) represents expectation values given by ensemble averaging. Fig. 2 shows the flow chart of the process followed. The coherence estimated in various polarization basis were analyzed over three distinct patches - an uncut teak plot which is the control plot, a plot cut during January and the third plot harvested during February. The analysis is explained in the next section.

\section{RESULTS}

Pol-InSAR coherence for all possible polarization combinations were derived for the time-series. Linear basis and Pauli-basis derived Pol-InSAR coherences exhibited sensitivity to change in forest structure while circular basis coherences was insensitive except LR polarization.

The undisturbed plot (Figure 3a) shows low coherence for all polarization (below 0.25) except for those image pairs whose perpendicular baseline was below $300 \mathrm{~m}$. While disturbed plots in (Figure $3 \mathrm{~b}$ and $3 \mathrm{c}$ ) showed increase in coherence with the onset of logging activities in all possible coherences except LL and RR polarizations which was insensitive to change in forest condition
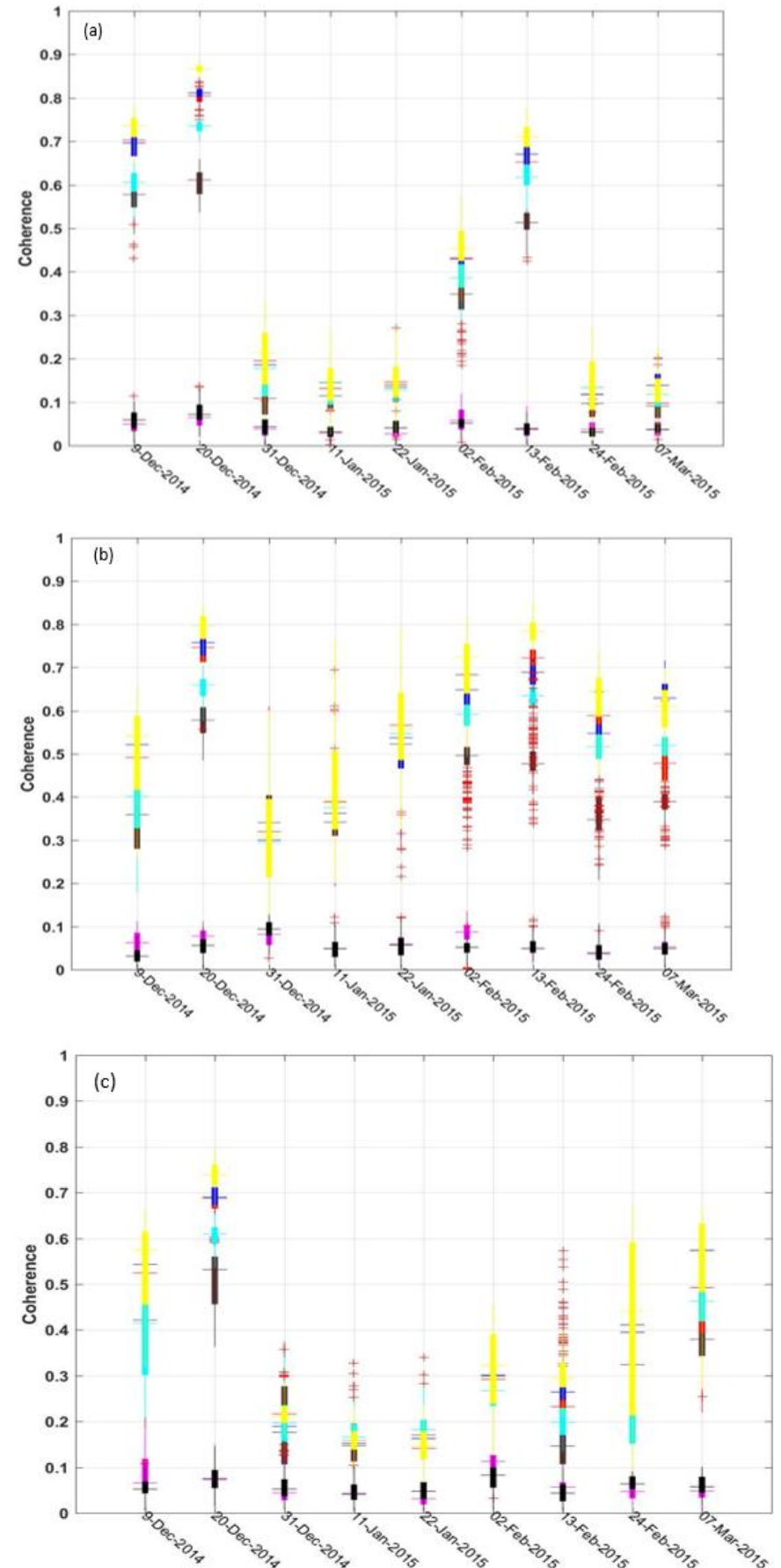

$-\mathrm{HH} \longrightarrow \mathrm{HV} \longrightarrow \mathrm{VV}-\mathrm{HH}+\mathrm{VV} \longrightarrow \mathrm{HH}-\mathrm{VV} \longrightarrow \mathrm{HV}+\mathrm{VH}-\mathrm{LL} \longrightarrow \mathrm{RR} \quad \mathrm{LR}$

Figure 3 Whisker plots showing trend for Pol-InSAR Coherence in all possible polarizations. (a) Represents the trend for an Uncut teak plot, (b) represents trend for teak plot cut in January and (c) represents trend for teak plantation cut in February

Among the 9 pair time-series, those data sets with perpendicular baseline more than $300 \mathrm{~m}$ were chosen in order to remove the effect of smaller baseline on coherence. The stratified plots (uncut, January cut and February cut) shown in figure 1 were 
utilized to calculate mean coherence for all possible polarizations and the trend with respect to forest disturbance was analyzed (Figure 4). The trend shows no change in coherence magnitude in the uncut forest plot, while disturbed plots showed clear deviation by increase in coherence with onset of progressive logging.

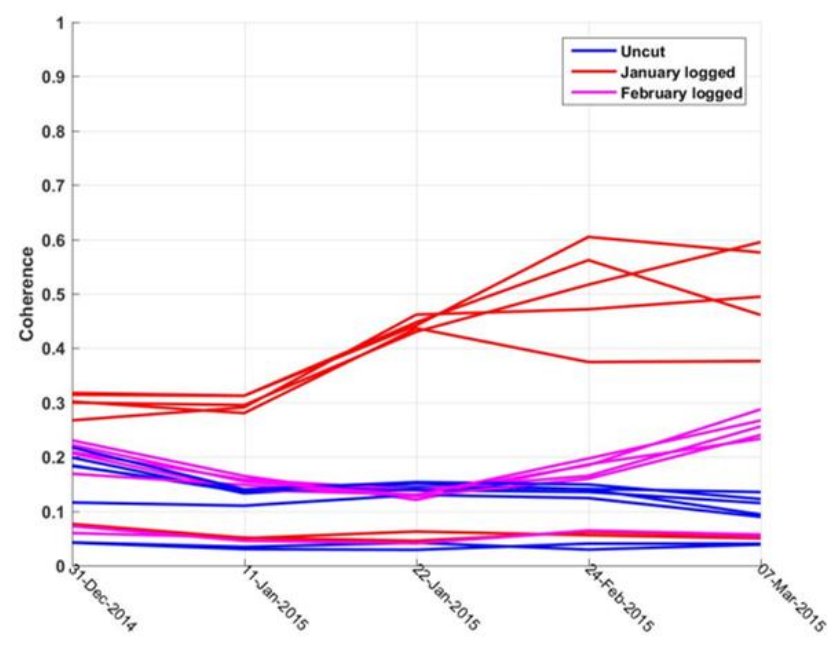

Figure 4 Pol-InSAR coherence trend for uncut (blue), January cut (red) and February cut (magenta)

\section{DISCUSSION}

High coherence observed in the $9^{\text {th }}$ Dec, $20^{\text {th }}$ Dec and $13^{\text {th }}$ Feb (Figure 2) was due to smaller baseline $(b<200 \mathrm{~m})$. Though the perpendicular baseline was in the range of 100 to 200 meters, negligible temporal decorrelation led to higher coherence. Since higher frequency has low penetration capability, $\mathrm{X}$ - band SAR signal interaction occurred only in the canopy region causing high volume decorrelation. Also continuous movement of leaves due to wind resulted in loss of coherence among the tandem pair even though the temporal decorrelation was negligible. These combination of factors has led to low coherence during the presence of vegetation which has been clearly depicted in Figure 3a and Figure 4, where the whiskers and mean coherence were well below 0.3 with less variation for all possible coherences.

Selective harvesting was carried out in a progressive manner from January to February. As the forest structure has been disturbed in January (Figure 3b) and February (Figure 3c), coherence increased gradually. This phenomenon was due to the removal of vegetation that resulted in conversion of vegetated land to bare surfaces or surface with vegetation debris. Removal of vegetation led to decrease in volume decorrelation and, increase in coherence due to the stable and exposed ground. Once the vegetation was clear-felled, it is a general silvicultural practice to burn the felling refuse(Nagaraja Bc et al., 2002). This practice makes the ground devoid of leaves, and hence eliminating the possibility of volume decorrelation due to the flushing of vegetation.

The compartment disturbed in January showed an increase in coherence trend throughout January due to the exposure of stable ground surface, and started to decrease at the end of February which might be due to the regeneration of vegetation. This assumption been supported by the February disturbed plot where an increasing trend was noticed for linear and Paulibasis coherences after $24^{\text {th }}$ February 2015 . The increase in coherence values during January (for January disturbed plots) and, during February (for plots disturbed in February) was due to the change of forest condition from mature forest to disturbed forest.

\section{CONCLUSIONS}

The study clearly depicts the potential of Tandem-X Pol-InSAR coherences to identify selective and progressive logging at an early stage which would highly benefit conservation measures. Further studies would be carried out to check the feasibility of using Pol-InSAR coherences for disturbance detection in mixed species plantation sites and natural forests.

\section{REFERENCES}

A. Pulella, P. C. Bispo, M. Pardini, F. Kugler, V. Cazcarra, M. Tello, K. Papathanassiou, H. Balzter, I. Rizaev, M. N. Santos, J. R. dos Santos, L. S. Araujo, K. Tansey, 2017. Tropical forest structure observation with TanDEM-X data, in: 2017 IEEE International Geoscience and Remote Sensing Symposium (IGARSS). Presented at the IEEE, pp. 918-921. https://doi.org/10.1109/IGARSS.2017.8127102

Khati, U., Singh, G., Ferro-Famil, L., 2017. Analysis of seasonal effects on forest parameter estimation of Indian deciduous forest using TerraSAR-X PolInSAR acquisitions. Remote Sens. Environ. 199, 265-276. https://doi.org/10.1016/j.rse.2017.07.019

Kobayashi, S., Omura, Y., Sanga-Ngoie, K., Yamaguchi, Y., Widyorini, R., Fujita, M.S., Supriadi, B., Kawai, S., 2015. Yearly Variation of Acacia Plantation Forests Obtained by Polarimetric Analysis of ALOS PALSAR Data. IEEE J. Sel. Top. Appl. Earth Obs. Remote Sens. 8, 5294-5304. https://doi.org/10.1109/JSTARS.2015.2487503

Nagaraja Bc, Jaganatha Rao, Murali Ks, D.M. Bhat, N.H.Ravindranath, 2002. Review of Silvicultural practices adopted in India: Its implications on Participatory Forest Management. https://doi.org/10.13140/rg.2.2.11202.79040

Olesk, A., Voormansik, K., Põhjala, M., Noorma, M., 2015. Forest change detection from Sentinel-1 and ALOS-2 satellite images, in: Synthetic Aperture Radar (APSAR), 2015 IEEE 5th Asia-Pacific Conference On. IEEE, pp. 522-527.

Øystein Aasaaren, Mario Boccucci, Tim Boyle, Tim Clairs, Marcus Colchester, Barney Dickson, Emily Dunning, Estelle Fach, Julie Greenwalt, Elspeth Halverson, Kristen Hite, Peter Holmgren, Jason Jabbour, Nina Kantcheva, Tim Kasten, Yemi Katerere, Denise Martinez, Francesco Martone, Charles McNeill, Lera Miles, Pablo Pacheco, Clea Paz-Rivera, Matea Osti, Wahida Patwa-Shah, Ravi Prabhu, Greg Reams, Cheryl Rosebush, Linda Rosengren, Gaya Sriskanthan, Tiina Vahanen, Joberto Veloso de Freitas, 2011. Perspectives on REDD+. UN-REDD.

Reid, W.V., Millennium Ecosystem Assessment, World Resources Institute (Eds.), 2005. Ecosystems and human wellbeing: synthesis; a report of the Millennium Ecosystem Assessment. Island Press, Washington, DC. 